Article

\title{
Field Induced Slow Magnetic Relaxation in a Non Kramers Tb(III) Based Single Chain Magnet
}

\author{
Ajit Kumar Kharwar ${ }^{\circledR}$, Arpan Mondal ${ }^{D}$ and Sanjit Konar* \\ Department of Chemistry, Indian Institute of Science Education and Research Bhopal, Bhopal Bypass Road, \\ Bhauri, Bhopal 462 066, India; ajitkharwar@iiserb.ac.in (A.K.K.); arpan16@iiserb.ac.in (A.M.) \\ * Correspondence: skonar@iiserb.ac.in; Tel.: +91-755-669-1313; Fax: +91-755-669-2392
}

Received: 29 October 2018; Accepted: 17 December 2018; Published: 19 December 2018

\begin{abstract}
Herein, we report a novel $\mathrm{Tb}$ (III) single chain magnet with the chemical formulae $\left[\mathrm{Tb}\left(\mu-\mathrm{OH}_{2}\right)(\mathrm{phen})(\mu-\mathrm{OH})(\mathrm{nb})_{2}\right]_{\mathrm{n}}$ by using 4-nitrobenzoic acid $(\mathrm{Hnb})$ and 1,10-phenanthroline (phen) as ligand system. The single-crystal $\mathrm{X}$-ray diffraction reveals that 4-nitrobenzoic acid acts as a monodentate ligand, water and hydroxyl ions are the bridging ligand and the phen serves as a bidentate chelating ligand. The static magnetic susceptibility measurement (from $2 \mathrm{~K}$ to $300 \mathrm{~K}$ ) shows ferromagnetic interaction at very low temperature (below $6 \mathrm{~K}$ ). The alternating current (AC) susceptibility data of the complex show temperature and frequency dependence under an applied 2000 Oe DC (direct current) field. The phen moiety behaves as an antenna and enables the complex to show the green light fluorescence emission by absorption-energy transfer-emission mechanism. To calculate the exchange interaction, broken symmetry density functional theory (BS-DFT) calculations have been performed on a model compound which also reveals weak ferromagnetic interaction. Ab initio calculations reveals the anisotropic nature $\left(g_{z}=15.8, g_{y}, g_{y}=0\right)$ of the metal centre and the quasi doublet nature of ground state with small energy gap and that is well separated from the next excited energy state.
\end{abstract}

Keywords: Non-Kramer lanthanide; magnetic anisotropy; exchange interaction; single chain magnet

\section{Introduction}

Single molecule magnets (SMMs) have attracted great attention due to their potential applications in the field of quantum computing, molecular spintronics, magneto-optics and high density data storage [1-4]. These low dimensional magnets, such as single ion magnet (SIM), single molecule magnet (SMM) [5,6] and single chain magnet (SCM) [7-9] show slow magnetic relaxation due to the presence of an energy barrier between different $\mathrm{m}_{\mathrm{J}}$ states. The height of energy barrier of magnetization reversal $\left(U_{\text {eff }}\right)$ depends upon the ground spin state and the magnetic anisotropy of the metal centre [10]. In SCMs, it is additionally affected by the intrachain interactions between the metal centres and the orientation of anisotropic axis for individual metal ions. Lanthanide elements are most preferable metal ions to achieve the high ground spin state value and by choosing the suitable ligand field high anisotropy can also be obtained [11-13]. Out of all molecular magnets the single chain magnets (SCMs) have shown a great importance due to its tune-ability towards the creation of anisotropic axes with high exchange interactions and dipolar interactions [14-17]. This leads to an enhancement to the effective energy barrier of magnetization reversal $\left(U_{\text {eff }}\right)$ and stimulate the hysteresis loop with large coercive field [18,19]. Huge numbers of SCMs have been constructed from 3d metals [20-22], 3d-radical [23,24], $3 \mathrm{~d}-3 \mathrm{~d}$ [25-27], 3d-5d [28,29], 3d-4f [30] and 4f-radical systems [31] and characterized. Terbium is one of the most preferred non-Kramer lanthanide elements for the design of SIMs [32-36], SMMs [37-40], due to its high intrinsic magnetic anisotropy which favours the slow relaxation of magnetization; however, terbium based SCMs are relatively less explored [41]. In 2005, Bernot et al. reported a series 
of rare earth element based single chain magnet using radical as a bridging ligand, where $\mathrm{Tb}$ (III) based SCM has also been reported [18]. In 2012, Pasca et al. reported a cyanido bridged one dimensional chain of tungsten and terbium [42]. In 2012, Liu et al. and in 2014, Hu et al. reported Tb(III) based 1D chain where the bridging ligand was the basic unit of nitronyl nitroxide based radical [43,44]. In 2016, Turta et al. reported a carboxylate bridged $\mathrm{Tb}$ (III) SCM by using $\alpha$-furon carboxylic acid [41].

Interestingly, $\mathrm{Tb}(\mathrm{III})$ based co-ordination polymers and complexes may also be considered as luminescent materials [45] and their emission can be explained by absorption-energy transfer-emission mechanism [46]. This can be achieved by using an attached ligand "antenna" which can absorb light and then transfers the energy to sensitize metal centre $\mathrm{Tb}(\mathrm{III})$ ) efficiently, eventually emitting the characteristic lanthanide bands [47]. Pyridine based lanthanide complexes are very well studied in the arena of luminescence, particularly 1,10-phenathroline which is having three aromatic rings and very well known for sensitizing $\mathrm{Ln}^{3+}$ Ions $[48,49]$.

Even though there are many SCMs have been reported but the main challenges are to achieve the strong Ising type anisotropy in magnetic centres and weak inter-chain interaction [14] to achieve best results. Herein, we report the synthesis, characterization, structure determination, magnetic study, luminescence property study and ab initio calculation of the $\mathrm{Tb}(\mathrm{III})$ based single chain magnet, $\left[\mathrm{Tb}\left(\mu-\mathrm{OH}_{2}\right)(\text { phen })(\mu-\mathrm{OH})(\mathrm{nb})_{2}\right]_{\mathrm{n}}$ (Complex 1) by using 4-nitrobenzoic acid $(\mathrm{Hnb})$ and 1,10-phenanthroline (phen).

\section{Result and Discussion}

\subsection{Synthesis and Spectral Characterization}

The complex 1 was obtained by the reaction of phen, 4-nitrobenzoic acid and $\mathrm{TbCl}_{3} \cdot 6 \mathrm{H}_{2} \mathrm{O}$ by using water and ethanol as solvent under solvo-thermal condition by following the synthetic procedure reported in literature [50]. The colourless crystals were manually separated from the reaction mixture for the further characterization and measurements.

The complex 1 was crystallized in the orthorhombic space group Pnma with $\mathrm{Z}=4$. The complex 1 shows a zig-zag chain with $\left[\mathrm{N}_{2} \mathrm{O}_{6}\right]$ eight-coordinate $\mathrm{Tb}(\mathrm{III})$ metal ions propagated by $\mu_{2}-\mathrm{H}_{2} \mathrm{O}$ and $\mu_{2}-\mathrm{OH}^{-}$hetero-bridges. As shown in Figure 1a (basic structural unit), the $\mathrm{N}_{2} \mathrm{O}_{6}$ co-ordination sphere of centrosymmetric $\mathrm{Tb}(\mathrm{III})$ ion is occupied by one chelating phen molecule (bidentate), two carboxylate $\mathrm{O}$ atoms (monodentate) from two symmetric 4-nitrobenzoate anions, two bridging hydroxyl groups and two bridging water molecules. The systematic analysis of the co-ordination geometry around the metal centre using SHAPE 2.1 program [51] reveals the approximately triangular dodecahedron coordination sphere of the $\mathrm{Tb}(\mathrm{III})$ in complex 1 with $\mathrm{D}_{2 d}$ geometry having the agreement factor of 0.723 (detailed geometric analysis is described in Table S2). A detailed comparisons reveal that the complex 1 has an apparent shortest Tb1-O1 bond (2.230(2) $\AA$ ) as compared to already known $\mathrm{Tb}$ (III) based single chain magnets [43] (Table S4). The appearance of the shortest $\mathrm{Tb} 1-\mathrm{O} 1_{\text {hydroxyl }}$ bond may significantly increase the single-ion anisotropy of the oblate $\mathrm{Tb}(\mathrm{III})$ spin responsible for the slow magnetic relaxation. Notably, the $\mu_{2}-\mathrm{OH}^{-}$and $\mu_{2}-\mathrm{H}_{2} \mathrm{O}$ bridges and $\mathrm{Tb}$ (III) ions lie in the same equatorial plane. Along the crystallographic $a$ axis, the $\mathrm{Tb}(\mathrm{III})$ ions are bridged by pairs of $\mu_{2}-\mathrm{H}_{2} \mathrm{O}$ and $\mu_{2}-\mathrm{OH}^{-}$groups to generate an infinite zig-zag chain (Figure $1 \mathrm{c}$ ). The bridging angles of $\angle \mathrm{Tb} 1-\mathrm{O} 2 / \mathrm{O} 1-\mathrm{Tb}^{1}(1=-1 / 2+\mathrm{x},+\mathrm{y}, 3 / 2-\mathrm{z})$ are $103.49^{\circ}(8)$ and $118.60^{\circ}(10)$ for water and hydroxyl bridges, respectively and the intrachain Tb1(III) $\cdots \mathrm{Tb}^{1}(\mathrm{III})(1=-1 / 2+\mathrm{x},+\mathrm{y}, 3 / 2-\mathrm{z})$ distance is 3.896 $\AA$ (2). Apparently, the $\mathrm{Tb}(\mathrm{III}) \cdots \mathrm{Tb}$ (III) distance separated by $\mu_{2}-\mathrm{H}_{2} \mathrm{O}$ and $\mu_{2}-\mathrm{OH}^{-}$bridges is much shorter than those previously reported terbium(III) chains connected by carboxylate linkages and nitronyl nitroxide radical $(5.196-8.427 \AA)[43,44]$. The distinct chains present strong $\pi \cdots \pi$ stacking interactions of phen moiety with distances of $3.780 \AA$ (Figure S1a,b in the Supporting Information) and weak intrachain and interchain $\mathrm{C}-\mathrm{H} \cdots \mathrm{O}$ interaction (distances and angles have been mentioned in Table S3). This leads to the generation of a two-dimensional layer (Figure 2) with interchain $\mathrm{Tb} \cdots \mathrm{Tb}$ distance of $11.286 \AA$ which ensures lack of interchain magnetic exchange. 
a)

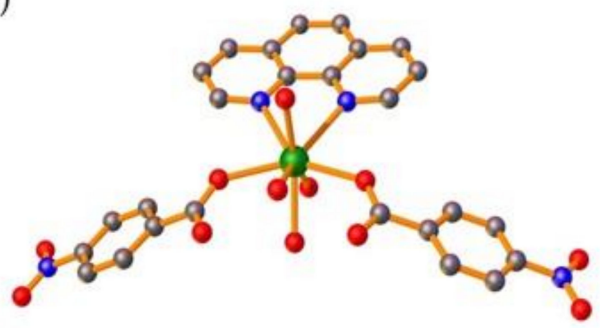

b)

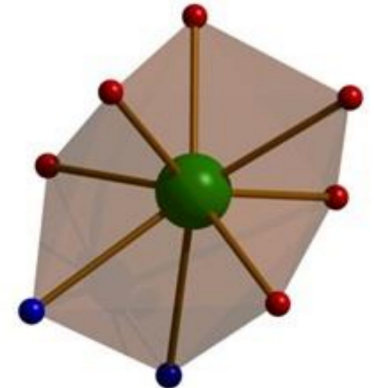

c)

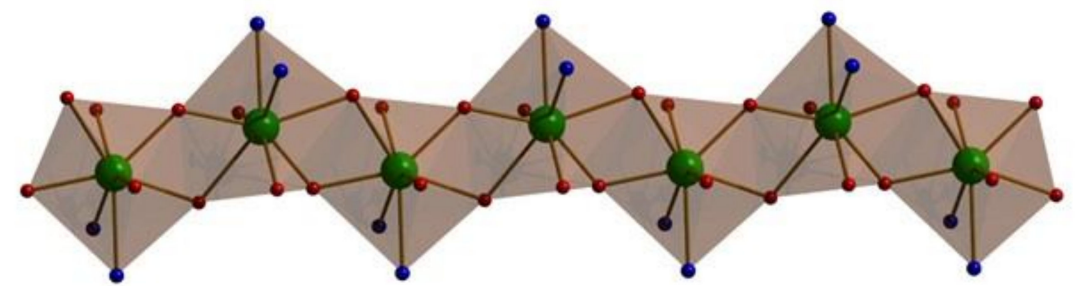

Figure 1. (a) Coordination sphere of $\mathrm{Tb}(\mathrm{III})$ ion the complex 1. (b) Polyhedron of coordination environment around $\mathrm{Tb}$ metal centre. (c) The one dimensional chain of complex 1 with $\mathrm{Tb}$ (III) ions propagated by water and hydroxyl bridges (Hydrogen atoms were omitted for clarity, colour code: $\mathrm{Tb}=$ green, $\mathrm{O}=$ red, $\mathrm{C}=$ grey, $\mathrm{N}=$ blue) .

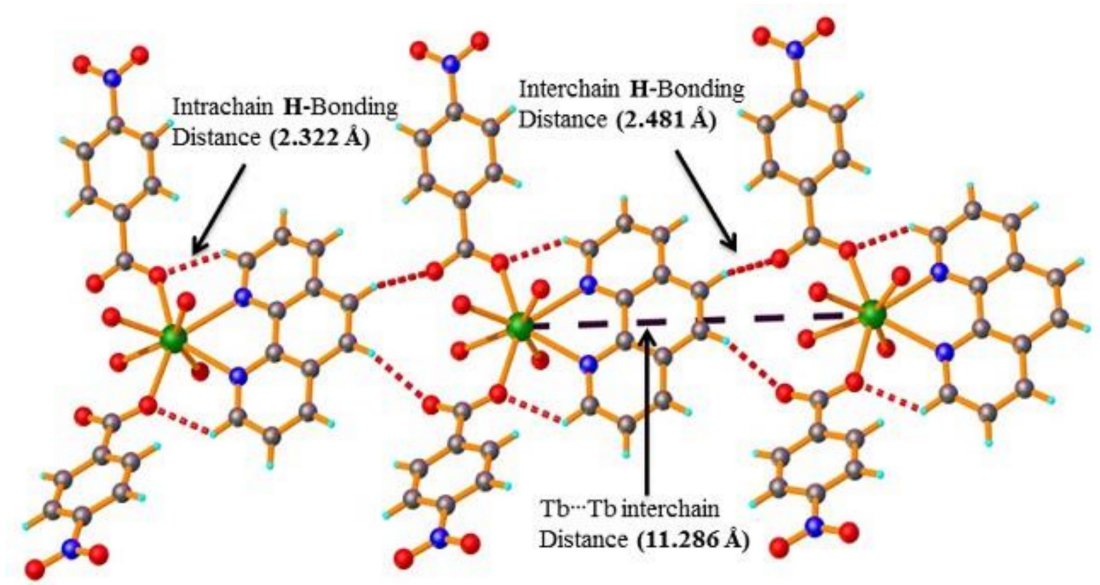

Figure 2. Intrachain and interchain $\mathrm{C}-\mathrm{H} \cdots \mathrm{O}$ interaction, with interchain $\mathrm{Tb} \cdots \mathrm{Tb}$ distance of $11.286 \AA$.

\subsection{IR Spectroscopy}

In the complex 1, the presence of aqua molecules and/or hydroxyl groups was confirmed by a strong and broad absorption band at $3412 \mathrm{~cm}^{-1}$ (characteristic stretching vibration of $\mathrm{O}-\mathrm{H}$ ) [52] (Figure S12 in the Supporting Information). The stretching frequency peaks at ca. 1622 and $1398 \mathrm{~cm}^{-1}$ are due to asymmetric $\left(v_{\text {asy }} \mathrm{COO}^{-}\right)$and symmetric $\left(v_{\mathrm{s}} \mathrm{COO}^{-}\right)$stretches of carboxylate, respectively. $v \mathrm{COO}^{-}\left[v_{\text {asy }}\left(\mathrm{COO}^{-}\right)-v_{\text {sym }}\left(\mathrm{COO}^{-}\right)\right]$is $224 \mathrm{~cm}^{-1}\left(>200 \mathrm{~cm}^{-1}\right)$, typical of monodentate carboxylate [53]. The stretching frequencies observed at ca. $1514 \mathrm{~cm}^{-1}$ and $1344 \mathrm{~cm}^{-1}$ reflect the asymmetric and symmetric stretching modes of the nitro group [54].

\subsection{PXRD and Thermal Stability}

PXRD was performed on complex 1 to confirm the bulk phase purity. The experimental PXRD of the bulk sample of complex $\mathbf{1}$ match well with the simulated pattern generated from the single crystal data which indicates the equitable phase purity (Figure S2). Thermogravimetric analysis (TGA) was performed in the temperature range of $30-800{ }^{\circ} \mathrm{C}$ under $\mathrm{N}_{2}$ flow with a heating rate of $10{ }^{\circ} \mathrm{C} \mathrm{min}-1$ 
that shows stability up to $150{ }^{\circ} \mathrm{C}$ followed by a gradual weight loss. Further heating resulted in the decomposition of whole framework finally leading to a residue which most likely amounts to the formation corresponding $\mathrm{Tb}_{2} \mathrm{O}_{3}$ (Figure $\mathrm{S} 11$ in the Supporting Information).

\subsection{Magnetic Properties}

\subsubsection{Direct Current Magnetic Susceptibility}

The magnetic susceptibility of the complex was measured on polycrystalline sample in the temperature range of 2-300 K under an applied DC field $0.1 \mathrm{~T}$. The phase purity of the complex 1 was confirmed by the good agreement of experimental powder $\mathrm{X}$-ray patterns with simulated ones (Figure S2). At room temperature, the $\chi_{\mathrm{M}} \mathrm{T}$ (where $\chi_{\mathrm{M}}$ is molar magnetic susceptibility) product is $12.07 \mathrm{~cm}^{3} \mathrm{~K} \mathrm{~mol}^{-1}$ for per mole of Tb atom [55] which is slightly larger than the expected to the value $C=g_{J}{ }^{2} J(J+1) / 8=11.8 \mathrm{~cm}^{3} \mathrm{~K} \mathrm{~mol}^{-1}$ for a free $\mathrm{Tb}(\mathrm{III})$ ion with a ground state ${ }^{7} \mathrm{~F}_{6}$ and $g_{J}=3 / 2(g=$ gyromagnetic ratio) [44,52]. Upon cooling down temperature, the value of the $\chi_{\mathrm{M}} \mathrm{T}$ decreases down to $10.48 \mathrm{~cm}^{3} \mathrm{~K} \mathrm{~mol}^{-1}$ at $6 \mathrm{~K}$ (Figure 3), this behaviour often observed in $4 f$ paramagnetic ions which are mainly ascribed to the depopulation of the excited Stark sublevels [56] and also the intra-chain antiferromagnetic exchange between the different $\mathrm{Tb}$ centres. Then it drastically increases to a value of $13.3 \mathrm{~cm}^{3} \mathrm{~K} \mathrm{~mol}^{-1}$ after further cooling to $2 \mathrm{~K}$ which indicates the presence of weak ferromagnetic interaction between the $\mathrm{Tb}$ ions in the 1D chain.

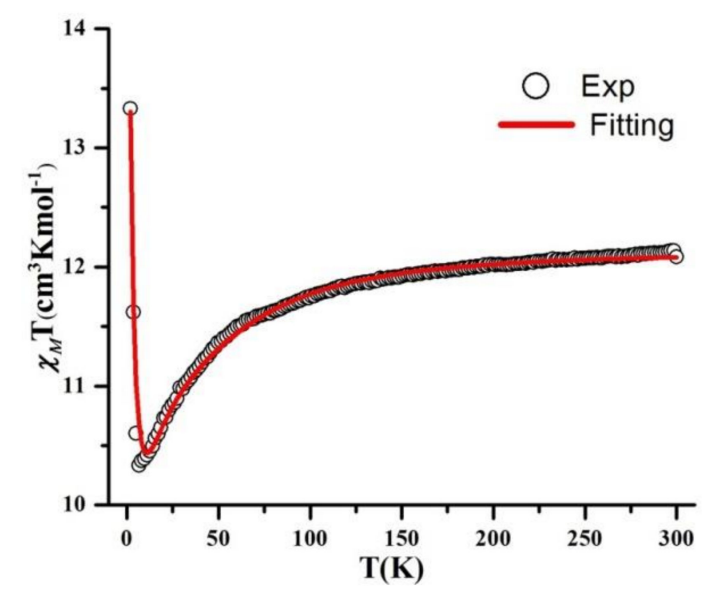

Figure 3. $\chi_{M} \mathrm{~T}$ versus $T$ plots at 1 KOe for complex 1 .

The field dependence of magnetization was measured at different temperature and in range of field 0-7 T. It shows rapid increase of the magnetization occurs at low magnetic field and with increasing the magnetic field it gradually increases and reached up to the value $4.95 N \mu_{B}$ at $7 \mathrm{~T}$ (Figure 4a). The sigmoidal nature of the curve also indicates the weak interactions between the Tb centres. This value is much smaller than the theoretical magnetization saturation value of $9 N \mu_{B}$. Furthermore the magnetization value do not saturate even at available highest magnetic field. In addition the reduced magnetization curve (Figure $4 \mathrm{~b}$ ) do not collapse on the same master curve which can be attributed to the presence of pseudo ground doublet and the significant anisotropy for Tb centre caused by the crystal field effect [57].

In addition to get the quantitative information about the extent of ferromagnetic interaction, the programme PHI [58] with crystal-field (CF) perturbation was employed to fit the magnetic susceptibility and magnetization. The following Hamiltonian has been used for slightly distorted $D_{2 \mathrm{~d}}$ symmetry as given in Equation (1).

$$
\hat{H}_{\mathrm{CF}}=-2 J\left(S_{1} \cdot S_{2}\right)+B_{0}^{2} O_{0}^{2}+B_{0}^{4} O_{0}^{4}+B_{0}^{6} O_{0}^{6}
$$

$\left(J, B_{q}^{k}, O_{q}^{k}\right.$ are the exchange interaction, crystal field parameter and Stevens operator respectively). 
The exchange interaction and crystal field parameters (Table 1) obtained by the concurrent fitting of $\chi_{\mathrm{M}} T$ versus $T$ and $M / N \mu_{B}$ versus $H$ plots. With the above Hamiltonian the fitting data is in good agreement with the experimental data especially at low temperature. Also, we have included mean field term as dipole-dipole interaction during the fitting which results $J_{e x}=+0.107 \mathrm{~cm}^{-1}$ and $J_{\text {dip }}=$ $+0.009 \mathrm{~cm}^{-1}$ (can be neglected). The best fit gives $J_{e x}=+0.107 \mathrm{~cm}^{-1}$ and $\mathrm{R}=0.306 \times 10^{-6}(\mathrm{R}=$ $\left.\Sigma\left[\left(\chi_{\mathrm{M}} \mathrm{T}\right)_{\mathrm{obsd}}-\left(\chi_{\mathrm{M}} \mathrm{T}\right)_{\text {calcd }}\right]^{2} / \Sigma\left[\left(\chi_{\mathrm{M}} \mathrm{T}\right)_{\mathrm{obsd}}\right]^{2}\right)$ which indicated weak ferromagnetic interaction present between the $\mathrm{Tb}$ centres.

Table 1. Exchange coupling and crystal field parameters of complex $\mathbf{1}$.

\begin{tabular}{ccc}
\hline Complex 1 & Fitting $\left(\mathbf{c m}^{-\mathbf{1}}\right)$ & From Calculations $\left(\mathbf{c m}^{\mathbf{- 1}}\right)$ \\
\hline $\begin{array}{c}\text { Exchange Coupling Parameter }(J) \\
\text { Crystal Field Parameters }\end{array}$ & +0.06 & \\
$\left(B_{0}^{2}, B_{0}^{4}, B_{0}^{6}\right)$ & $(-566,155,5.4)$ & $(-356,78.8,4.6)$ \\
\hline
\end{tabular}

a)

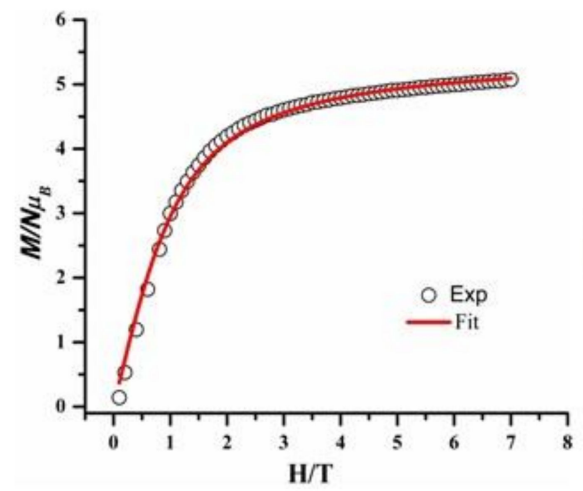

b)

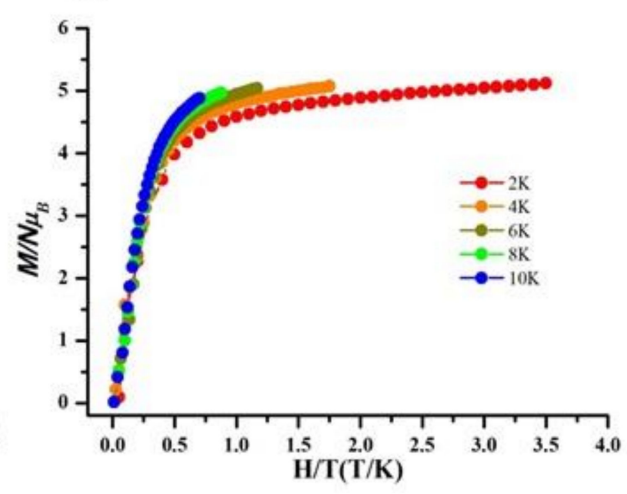

Figure 4. (a) DC magnetization as a function of the applied field, $\mathrm{M}(\mathrm{H})$, at $4 \mathrm{~K}$ and, (b) reduced magnetization plot in the field range of $0-7 \mathrm{~T}$ and temperature range of $2-10 \mathrm{~K}$ for complex $\mathbf{1}$.

\subsubsection{Dynamic Magnetic Measurement}

To pursue the SMM behaviour alternating current (ac) magnetic susceptibility data were collected in the temperature range of $2-10 \mathrm{~K}$ under zero dc field with a constant ac field of 3.5 Oe of oscillating frequencies. The in-phase $\chi_{\mathrm{M}}{ }^{\prime}$ ac susceptibility data show no frequency dependence between $2 \mathrm{~K}$ and $10 \mathrm{~K}$ as shown in Figure S3b in the Supporting Information. While the $\chi_{\mathrm{M}}{ }^{\prime \prime}(\mathrm{T})$ curves exhibit small frequency dependence, hinting at slow relaxation at lower temperature however no clear peak maxima is observed above $2 \mathrm{~K}$ which is mainly due to the fast quantum tunnelling of magnetization $[59,60]$ (Figure S5a). We performed ac measurements on complex 1 at different fields in the range of 500 Oe to 3000 Oe and optimal dc field of 2000 Oe was selected because it invokes the slowest relaxation in the range of in the 2000-3000 Oe fields (see Figures S6-S9, Supporting Information). So to suppress the QTM and have more insight of SMM behaviour, ac susceptibility data have been collected with an applied dc field of 2000 Oe. At 2000 Oe dc field the frequency dependency of out of phase ac susceptibility (Figure S10) and the temperature dependency of in phase $\left(\chi_{\mathrm{M}^{\prime}}\right)$ (Figure $5 \mathrm{~b}$ ) and out of phase $\left(\chi_{M}{ }^{\prime \prime}\right)$ (Figure 5a) ac susceptibility clarifies the SMM behaviour of complex 1. Although the values of $\chi_{\mathrm{M}}$ " at higher temperature goes negative (Figure 5a) [54,61] and lower than the expected range also indicates the small fractions of the molecules are participating the slow relaxation of magnetization. And may be for the same reason the $\chi_{\mathrm{M}}{ }^{\prime \prime}$ values are quite smaller as compared to $\chi_{\mathrm{M}}{ }^{\prime \prime}$ value in the AC susceptibility plots (Figure 5a,b). 

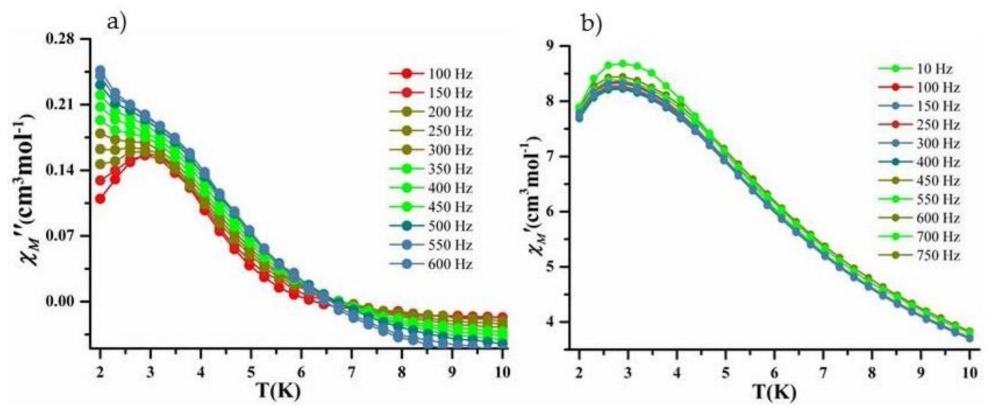

Figure 5. (a) Out of phase $\left(\chi_{M}^{\prime \prime}\right.$ vs. T) and, (b) in phase $\left(\chi_{M}^{\prime}\right.$ vs. T) AC plot for complex 1 at 2000 Oe dc field.

As $\chi_{\mathrm{M}}$ " versus $\mathrm{T}$ plots do not show any peak maxima above $2 \mathrm{~K}$, so the $\tau_{0}$ the energy barrier $\left(U_{\text {eff }}\right)$ cannot be determined by using the Arrhenius method [62,63]. So by using another method, which assumes that there is only one single relaxation process with one energy barrier and one time constant that can be extracted by the following equation (Debye Model) [64],

$$
\ln \left(\chi_{\mathrm{M}^{\prime \prime}} / \chi_{\mathrm{M}}{ }^{\prime}\right)=\ln \left(\omega \tau_{0}\right)+U_{\mathrm{eff}} / k_{\mathrm{B}} T \ldots \ldots \ldots \ldots \ldots \ldots \ldots 2(\omega=\text { angular frequency }) .
$$

The best fit of Debye equation yielded an energy barrier of $2.5 \mathrm{~K}$ (Figure 6) and $\tau_{0}$ is $6.6 \times 10^{-7} \mathrm{~s}$. It is worth noting that these are only approximate values and therefore should be taken with caution [61]. The low value of energy barrier in case of non-Kramers ion mainly attributed to the quantum tunnelling of magnetization (QTM) and Raman processes (occurring through some virtual states) which are more favourable for slow relaxation [65].

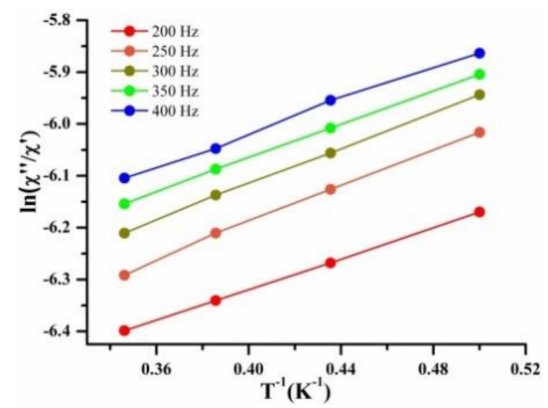

Figure 6. The solid lines represent fit to the Debye model according to Equation (1).

\subsection{Theoretical Calculations}

\subsubsection{Exchange Interaction Calculations}

Due to first order spin-orbit coupling effects the wave function of the energy states on $\mathrm{Tb}$ are complex and multi-determinantal. Thus BS-DFT cannot be applied directly for the description of exchange interaction. Recently Vieru et al. reported [66] an approach regarding this problem where anisotropic metal centre was replaced by isotropic Gd centre keeping the position constant for other atoms. So, we have employed similar approach (See Supporting Information for details), by replacing $\mathrm{Tb}$ centre by isotropic $\mathrm{Gd}$ centre which can be well described by single determinant wave function and remaining the position constant for other atoms. We have computed the exchange coupling between the adjacent $\mathrm{Gd}$ centres and then we rescaled the obtained $J=+0.044 \mathrm{~cm}^{-1}(\mathrm{Gd}-\mathrm{Gd})$ from the spin $7 / 2$ of $\mathrm{Gd}$ and the spin 3 of Tb by multiplying former by $49 / 36$. This rescaling procedure can also give a satisfactory estimation of the exchange coupling between the anisotropic centres. Even with its simplicity, this approach produced reliable result to the description of exchange coupling between the anisotropic systems for a series of multimetallic complexes $[67,68]$. The calculated exchange between the two Tb centres is $+0.06 \mathrm{~cm}^{-1}$ is given in Table 1 (detailed explanations are given in Tables S6 and S7 in the Supporting Information) which is very close to the experimental value obtained from the 
fitting. In addition the magnetic orbitals of Gd centre (Figure 7) in complex 1 shows a tails towards the bridging $\mathrm{O}$ atoms which connect the next $\mathrm{Gd}$ atoms, resulting very weak ferromagnetic interaction between the magnetic centres.
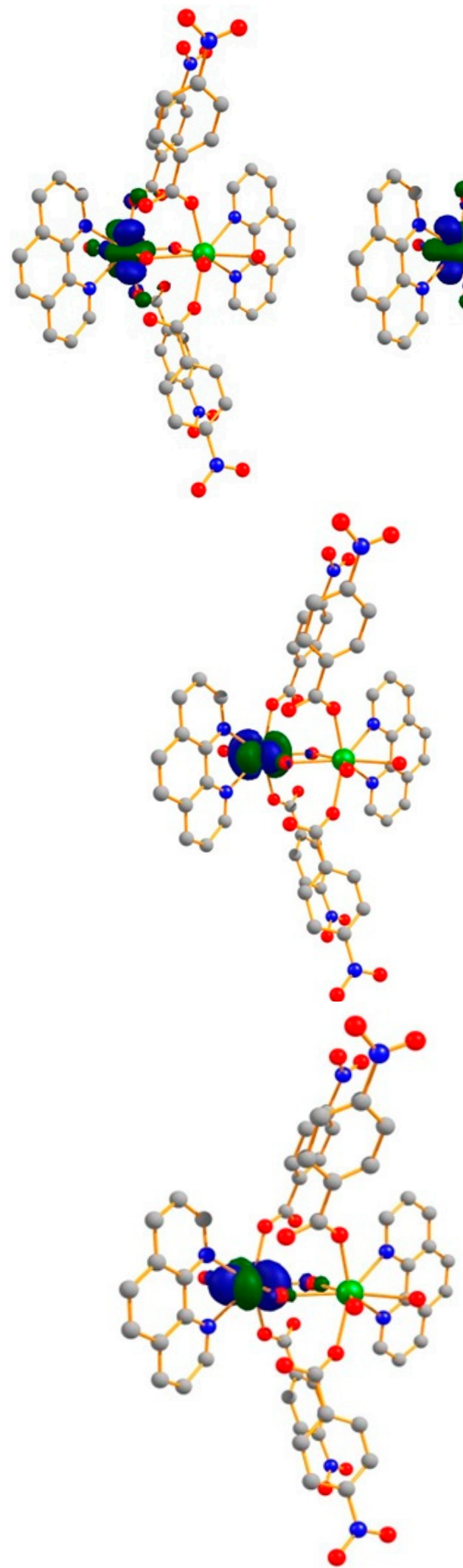
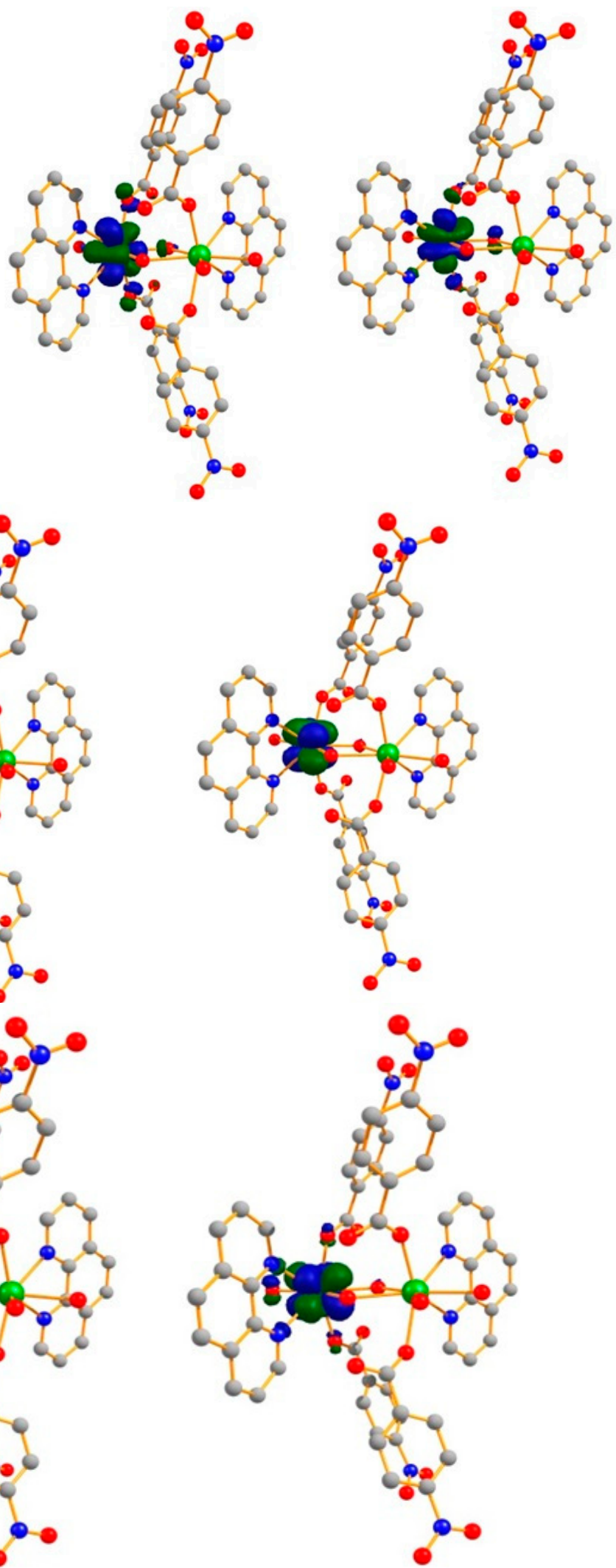

Figure 7. Magnetic orbitals on one of the Gd centre in complex 1. 


\subsubsection{Ab Initio Calculations}

To estimate the energy levels structure of $\mathrm{Tb}(\mathrm{III})$ multiplet and the anisotropy of the low-lying states we have performed ab initio calculations using CASSCF/RASSI-SO/SINGLE_ANISO method as implemented in MOLCAS 8.2 (See Supporting Information for details). The calculations were performed on the experimentally determined X-ray structure without optimizations. In this case all $\mathrm{Tb}$ (III) ions are in similar environment. Thus, we have used a cluster model where one $\mathrm{Tb}$ (III) ions and two $\mathrm{La}(\mathrm{III})$ ions are present. In this model also we have included bridging $\mathrm{OH}^{-}$and $\mathrm{H}_{2} \mathrm{O}$ molecule in the both side of the studied Terbium ion. We have consider 8 electrons in 7 ' $4 \mathrm{f}^{\prime}$ ' orbitals [CAS $\left.(8,7)\right]$ in the active space. The CASSCF calculations were performed with 7 septets, 140 quintets, 195 triplets. Further we have noticed that the first excited state is separated from the ground by $9.4 \mathrm{~cm}^{-1}$ as shown in the Figure $8 \mathrm{~b}$. The ground state is mainly composed of state $\mathrm{M}_{\mathrm{J}}=6$ with some mixture from $\mathrm{M}_{\mathrm{J}}$ $=5$. So the two lowest energy states can be considered as a quasi-doublet. In addition, the second excited and third excited states are at relatively higher energy level, $91 \mathrm{~cm}^{-1}$ and $171 \mathrm{~cm}^{-1}$ respectively (Figure $8 b$ ). The uniaxial magnetic anisotropy is also observed in the ground state with $g_{z}=15.8, g_{y}$, $\mathrm{g}_{\mathrm{y}}=0$ which is nearly perpendicular to the $\mathrm{c}$ axis (Figure 8a). Again as we move from the ground state to the higher excited states the uniaxial nature of the states are gradually decreases. The two non-degenerate ground states at low temperature and other excited states in high temperature are also expected for non-Kramers ions [44].
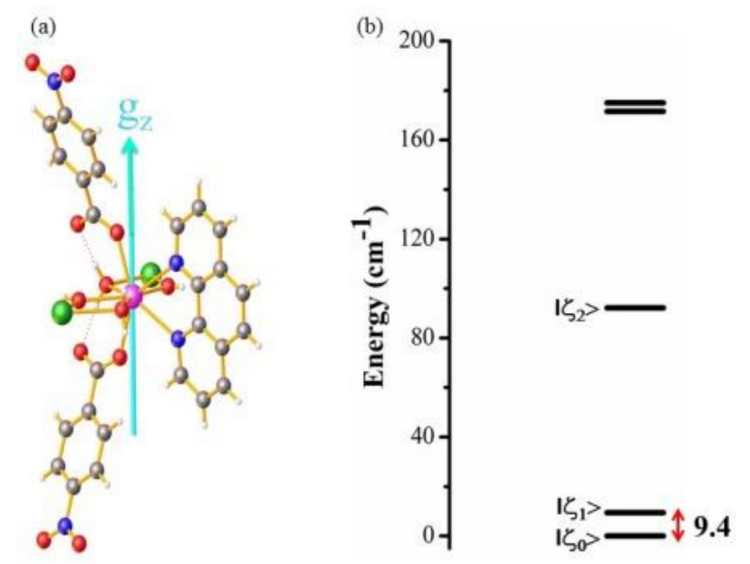

Figure 8. (a) Ab initio computed orientation of the principal magnetization axis of the ground state (b) $\mathrm{CF}$ split energy levels calculated by ab initio for $\mathrm{Tb}(\mathrm{III})$ centre in complex $\mathbf{1}$.

\subsection{Photoluminescence}

The unique photo-physical properties of lanthanide complexes make them attractive class of compound and because of the minimally perturbed $\mathrm{f}-\mathrm{f}$ electronic transitions they show sharp line like emission with high colour purity [69]. Spin and Laporte rules of fluorescence emission forbids these electronic transitions partly which results the longer excited sate lifetimes (millisecond to microsecond range) $[70,71]$. The introduction of strong light-harvesting chromophore can solve the problem of low extinction coefficients in lanthanide complexes by a process known as the antenna effect (absorption of light by chromophore ligand and transfer of energy to the metal centre) [72-74].

In the present case the emission spectrum of complex 1 displays characteristic strong emission bands of $\mathrm{Tb}$ (III) at 485, 543, 585 and $617 \mathrm{~nm}$ upon excitation at $300 \mathrm{~nm}$ (Figure 9) [75-77]. These bands are assigned to transitions between the first excited state, ${ }^{5} \mathrm{D}_{4}$ and the ground-state multiplet ${ }^{7} \mathrm{~F}_{J}(J=6$, $5,4,3)$. The green luminescence emission of complex 1 was observed because of the strong ${ }^{5} \mathrm{D}_{4} \rightarrow{ }^{7} \mathrm{~F}_{5}$ transition at $543 \mathrm{~nm}$. 


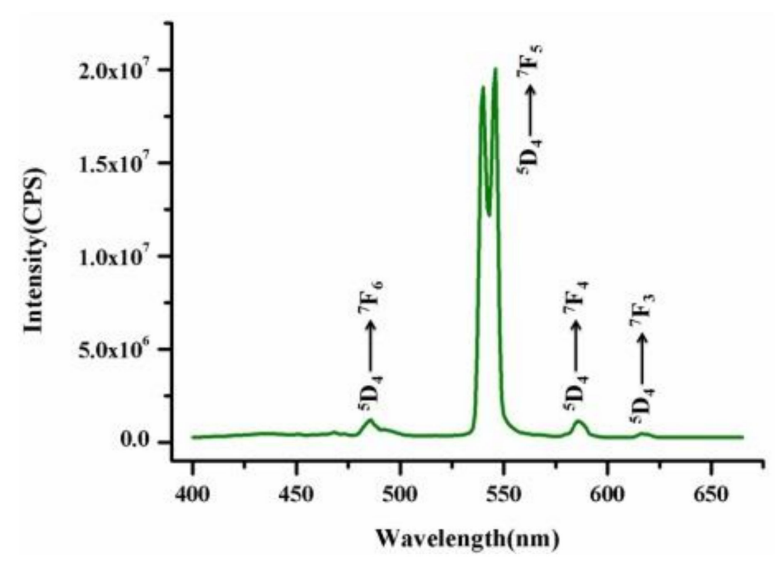

Figure 9. Solid state fluorescence emission spectra of complex $\mathbf{1}$ at room temperature.

\section{Materials and Methods}

\subsection{Starting Materials}

All the reagents and solvents employed were commercially available and used without further purification. The synthetic reactions and work-up were done in the open air.

\subsection{Preparation of the Complex}

Synthesis of $\left[\mathrm{Tb}\left(\mu-\mathrm{OH}_{2}\right)(\text { phen })(\mu-\mathrm{OH})(n b)_{2}\right]_{n}$ (1). Hnb $(16.7 \mathrm{mg}, 0.1 \mathrm{mmol})$, phen $(60 \mathrm{mg}, 0.3 \mathrm{mmol})$ and $\mathrm{TbCl}_{3} \cdot 6 \mathrm{H}_{2} \mathrm{O}(36.4 \mathrm{mg}, 0.1 \mathrm{mmol})$ were added to a mixture of solvents containing distilled water $(5 \mathrm{~mL})$ and ethanol $(1 \mathrm{~mL})$. After $30 \mathrm{~min}$ of constant stirring the reaction mixture was transferred to Teflon vessel $(23.0 \mathrm{~mL})$ sealed in a stainless steel container and heated at $140{ }^{\circ} \mathrm{C}$ for $72 \mathrm{~h}$ under autogenous pressure. Colourless block-shaped crystals were obtained after cooling down the reaction mixture to the room temperature and washed with distilled water. The grown crystals were highly suitable for single-crystal $\mathrm{X}$-ray structural determination, separated manually and dried in air (yield: 34\%). Calcd. for $\mathrm{C}_{26} \mathrm{H}_{19} \mathrm{TbN}_{4} \mathrm{O}_{10}: \mathrm{C}, 44.21 ; \mathrm{H}, 2.71 ; \mathrm{N}, 7.93 \%$. Found: $\mathrm{C}, 44.06 ; \mathrm{H}, 2.611 ; \mathrm{N}, 7.88 \%$. IR $\left(\mathrm{KBr}, \mathrm{cm}^{-1}\right)$ : 3412 (s), 1948 (w), 1579 (s), $1514(\mathrm{~m}), 1398(\mathrm{~m}), 1344(\mathrm{~s}), 1097(\mathrm{w}), 858(\mathrm{w}), 792(\mathrm{w}), 723$ (w), $516(\mathrm{w})$.

\subsection{X-ray Data Collection and Structure Refinement}

Intensity data were collected on a Brüker APEX-II D8 venture diffractometer using a graphite monochromated Mo-K $\alpha$ radiation $(\lambda=0.71073 \AA)$ at $120 \mathrm{~K}$. Data collections were performed using $\phi$ and $\omega$ scan. Using Olex2 [78] as graphical interface, the structure was solved with the ShelXT [79] structure solution program using intrinsic phasing. The model was refined with ShelXL [79] with full matrix least squares minimisation on $F^{2}$. All non-hydrogen atoms were refined anisotropically. Crystallographic data for complex 1 have been summarized in Table S1. Bond lengths and angles are listed in Tables S4 and S5 in the Supporting Information.

\subsection{Physical Measurements}

The elemental analyses were performed on an Elementar Micro vario Cube elemental analyser. FTIR spectrum (4000-400 $\mathrm{cm}^{-1}$ ) was recorded for KBr pellets with a Perkin Elmer Spectrum BX spectrometer. Powder X-ray diffraction (PXRD) data were collected using a PANalytical EMPYREAN instrument $\left(\mathrm{Cu}-\mathrm{K}_{\alpha}\right.$ radiation). Magnetic measurements were performed by using a Quantum Design magnetometer. The measured values were corrected for the experimentally measured contribution of the sample holder, whereas the derived susceptibilities were corrected for the diamagnetism of the samples, estimated from Pascal's tables [55]. Absorption studies were recorded with an Agilent Cary 100 UV/Vis spectrophotometer. Thermogravimetric analysis was conducted with a 
Perkin-Elmer Thermogravimetric analyser with a heating rate of $10{ }^{\circ} \mathrm{C} \mathrm{min}^{-1}$ in the temperature range of $30-800{ }^{\circ} \mathrm{C}$. The photoluminescence spectral measurements were recorded with a Horiba Jobin Yvon Fluoromax-4 spectrofluorometer.

\section{Conclusions}

In conclusion, we have synthesized a new non-Kramers $\mathrm{Tb}$ (III) single chain magnet which shows ferromagnetic behaviour at very low temperature (below $6.1 \mathrm{~K}$ ) which is very well supported by the BS-DFT calculations. The complex also shows field induced slow relaxation of magnetization. The sharp luminescence of the complex confers its application in the field of multifunctional material. The ab initio calculations manifest the highly anisotropic nature of the Tb(III) SCM with $g_{z}=15.80$ and the quasi doublet nature of ground spin state with small energy gap which leads to fast relaxation. Future work will adjoin the appropriate coordination sphere around the Ln(III) centre to create the high anisotropy and reasonable bridging ligand to have maximum exchange coupling for excellent SMM properties.

Supplementary Materials: Crystallographic data for the structural analysis have been deposited with the Cambridge Crystallographic Data Centre No. 1865187 for complex 1. Copy of the data can be obtained free of charge from the Director, CCDC, 12 Union Road, Cambridge CB2 1EZ, UK [fax: +44(0)-1223-336033; or e-mail: deposit@ccdc.cam.ac.uk or http:/ / www.ccdc.cam.ac.uk].

Author Contributions: A.K.K. performed the experiments; solved the crystal structure and analysed the magnetic data; A.M. conducted the theoretical calculations and S.K. supervised the overall work and organized the project.

Funding: S.K. acknowledges DAE-BRNS Government of India [Project No. 37(2)/14/09/2015/BRNS] and IISER Bhopal for generous financial support. A.K.K. thanks CSIR, India for fellowship. A.M. is thankful to IISER Bhopal for PhD fellowship.

Acknowledgments: We thank Siba Prasad Bera and Subhadip Roy for their valuable scientific support. The highperformance computing (HPC) facility at IISER Bhopal is gratefully acknowledged for the computational work.

Conflicts of Interest: The authors declare no conflict of interest.

\section{References}

1. Woodruff, D.N.; Winpenny, R.E.P.; Layfield, R.A. Lanthanide Single-Molecule Magnets. Chem. Rev. 2013, 113, 5110-5148. [CrossRef] [PubMed]

2. Sun, H.L.; Wang, Z.M.; Gao, S. Strategies towards single-chain magnets. Coord. Chem. Rev. 2010, 254, 1081-1100. [CrossRef]

3. Zhang, P.; Guo, Y.N.; Tang, J.K. Recent advances in dysprosium-based single molecule magnets: Structural overview and synthetic strategies. Coord. Chem. Rev. 2013, 257, 1728-1763. [CrossRef]

4. Goswami, S.; Mondal, A.K.; Konar, S. Nanoscopic molecular magnets. Inorg. Chem. Front. 2015, 2, 687-712. [CrossRef]

5. Dey, B.; Roy, S.; Mondal, A.K.; Santra, A.; Konar, S. Zero Field SMM Behavior and Magnetic Refrigeration in Rare Heterometallic Double Stranded Helicates of $\mathrm{Cu}_{2} \mathrm{Ln}_{2}(\mathrm{Ln}=\mathrm{Dy}, \mathrm{Tb}, \mathrm{Gd})$. Eur. J. Inorg. Chem. 2018, 2018, 2429-2436. [CrossRef]

6. Adhikary, A.; Sheikh, J.A.; Biswas, S.; Konar, S. Synthesis, crystal structure and study of magnetocaloric effect and single molecular magnetic behaviour in discrete lanthanide complexes. Dalton Trans. 2014, 43, 9334-9343. [CrossRef] [PubMed]

7. Zhang, W.-X.; Ishikawa, R.; Breedlove, B.; Yamashita, M. Single-chain magnets: Beyond the Glauber model. RSC Adv. 2013, 3, 3772-3798. [CrossRef]

8. Coulon, C.; Pianet, V.; Urdampilleta, M.; Clerac, R. Single-Chain Magnets and related systems. Struct. Bond. 2015, 164, 143-184.

9. Mondal, A.K.; Jena, H.S.; Malviya, A.; Konar, S. Lanthanide-Directed Fabrication of Four Tetranuclear Quadruple Stranded Helicates Showing Magnetic Refrigeration and Slow Magnetic Relaxation. Inorg. Chem. 2016, 55, 5237-5244. [CrossRef]

10. Dhers, S.; Feltham, H.L.C.; Brooker, S. A toolbox of building blocks, linkers and crystallisation methods used to generate single-chain magnets. Coord. Chem. Rev. 2015, 296, 24-44. [CrossRef] 
11. Liddle, S.T.; van Slageren, J. Improving f-element single molecule magnets. Chem. Soc. Rev. 2015, 44, 6655-6669. [CrossRef] [PubMed]

12. Adhikary, A.; Jena, H.S.; Khatua, S.; Konar, S. Synthesis and Characterization of Two Discrete Ln10 Nanoscopic Ladder-Type Cages: Magnetic Studies Reveal a Significant Cryogenic Magnetocaloric Effect and Slow Magnetic Relaxation. Chem. Asian J. 2014, 9, 1083-1090. [CrossRef] [PubMed]

13. Mondal, A.; Parmar, V.; Konar, S. Modulating the Slow Relaxation Dynamics of Binuclear Dysprosium(III) Complexes through Coordination Geometry. Magnetochemistry 2016, 2, 35. [CrossRef]

14. Bogani, L.; Vindigni, A.; Sessoli, R.; Gatteschi, D. Single chain magnets: Where to from here? J. Mater. Chem. 2008, 18, 4750-4758. [CrossRef]

15. Jassal, A.K.; Sran, B.S.; Suffren, Y.; Bernot, K.; Pointillart, F.; Cador, O.; Hundal, G. Structural diversity and photo-physical and magnetic properties of dimeric to $1 \mathrm{D}$ polymeric coordination polymers of lighter lanthanide(iii) dinitrobenzoates. Dalton Trans. 2018, 47, 4722-4732. [CrossRef]

16. Jassal, A.K.; Aliaga-Alcalde, N.; Corbella, M.; Aravena, D.; Ruiz, E.; Hundal, G. Neodymium 1D systems: Targeting new sources for field-induced slow magnetization relaxation. Dalton Trans. 2015, 44, 15774-15778. [CrossRef] [PubMed]

17. Jung, J.; Le Natur, F.; Cador, O.; Pointillart, F.; Calvez, G.; Daiguebonne, C.; Guillou, O.; Guizouarn, T.; Le Guennic, B.; Bernot, K. Experimental and theoretical evidence that electrostatics governs easy-axis orientation in DyIII-based molecular chains. ChemComm 2014, 50, 13346-13348. [CrossRef] [PubMed]

18. Bernot, K.; Bogani, L.; Caneschi, A.; Gatteschi, D.; Sessoli, R. A Family of Rare-Earth-Based Single Chain Magnets: Playing with Anisotropy. J. Am. Chem. Soc. 2006, 128, 7947-7956. [CrossRef]

19. Wang, X.; Li, Y.; Hu, P.; Wang, J.; Li, L. Slow magnetic relaxation and field-induced metamagnetism in nitronyl nitroxide-Dy(iii) magnetic chains. Dalton Trans. 2015, 44, 4560-4567. [CrossRef]

20. Liu, T.-F.; Fu, D.; Gao, S.; Zhang, Y.-Z.; Sun, H.-L.; Su, G.; Liu, Y.-J. An Azide-Bridged Homospin Single-Chain Magnet: [Co(2,2'-bithiazoline $\left.)\left(\mathrm{N}_{3}\right)_{2}\right]$ n. J. Am. Chem. Soc. 2003, 125, 13976-13977. [CrossRef]

21. Bernot, K.; Luzon, J.; Sessoli, R.; Vindigni, A.; Thion, J.; Richeter, S.; Leclercq, D.; Larionova, J.; van der Lee, A. The Canted Antiferromagnetic Approach to Single-Chain Magnets. J. Am. Chem. Soc. 2008, 130, 1619-1627. [CrossRef] [PubMed]

22. Xu, H.-B.; Wang, B.-W.; Pan, F.; Wang, Z.-M.; Gao, S. Stringing Oxo-Centered Trinuclear [MnIII $\left.{ }_{3} \mathrm{O}\right]$ Units into Single-Chain Magnets with Formate or Azide Linkers. Angew. Chem. Int. Ed. 2007, 46, 7388-7392. [CrossRef] [PubMed]

23. Caneschi, A.; Gatteschi, D.; Lalioti, N.; Sangregorio, C.; Sessoli, R.; Venturi, G.; Vindigni, A.; Rettori, A.; Pini, M.G.; Novak, M.A. Cobalt(II)-Nitronyl Nitroxide Chains as Molecular Magnetic Nanowires. Angew. Chem. Int. Ed. 2001, 40, 1760-1763. [CrossRef]

24. Miyasaka, H.; Madanbashi, T.; Sugimoto, K.; Nakazawa, Y.; Wernsdorfer, W.; Sugiura, K.-I.; Yamashita, M.; Coulon, C.; Clérac, R. Single-Chain Magnet Behaviour in an Alternated One-Dimensional Assembly of a MnIII Schiff-Base Complex and a TCNQ Radical. Chem. Eur. J. 2006, 12, 7028-7040. [CrossRef] [PubMed]

25. Clérac, R.; Miyasaka, H.; Yamashita, M.; Coulon, C. Evidence for Single-Chain Magnet Behaviour in a MnIII-NiII Chain Designed with High Spin Magnetic Units: A Route to High Temperature Metastable Magnets. J. Am. Chem. Soc. 2002, 124, 12837-12844. [CrossRef] [PubMed]

26. Wang, S.; Zuo, J.-L.; Gao, S.; Song, Y.; Zhou, H.-C.; Zhang, Y.-Z.; You, X.-Z. The Observation of Superparamagnetic Behaviour in Molecular Nanowires. J. Am. Chem. Soc. 2004, 126, 8900-8901. [CrossRef] [PubMed]

27. Pardo, E.; Cangussu, D.; Dul, M.-C.; Lescouëzec, R.; Herson, P.; Journaux, Y.; Pedroso, E.F.; Pereira, C.L.M.; Muñoz, M.C.; Ruiz-García, R.; et al. A Metallacryptand-Based Manganese(II)-Cobalt(II) Ferrimagnet with a Three-Dimensional Honeycomb Open-Framework Architecture. Angew. Chem. 2008, 120, 4279-4284. [CrossRef]

28. Choi, S.W.; Kwak, H.Y.; Yoon, J.H.; Kim, H.C.; Koh, E.K.; Hong, C.S. Intermolecular Contact-Tuned Magnetic Nature in One-Dimensional 3d-5d Bimetallic Systems: From a Metamagnet to a Single-Chain Magnet. Inorg. Chem. 2008, 47, 10214-10216. [CrossRef]

29. Harris, T.D.; Bennett, M.V.; Clérac, R.; Long, J.R. $\left[\mathrm{ReCl}_{4}(\mathrm{CN})_{2}\right]^{2-}$ : A High Magnetic Anisotropy Building Unit Giving Rise to the Single-Chain Magnets $(\mathrm{DMF})_{4} \mathrm{MReCl}_{4}(\mathrm{CN})_{2}(\mathrm{M}=\mathrm{Mn}, \mathrm{Fe}, \mathrm{Co}, \mathrm{Ni})$. J. Am. Chem. Soc. 2010, 132, 3980-3988. [CrossRef] 
30. Costes, J.-P.; Clemente-Juan, J.M.; Dahan, F.; Milon, J. Unprecedented $\left(\mathrm{Cu}_{2} \mathrm{Ln}\right) \mathrm{n}$ Complexes $\left(\mathrm{Ln}=\mathrm{Gd}^{3+}\right.$, $\mathrm{Tb}^{3+}$ ): A New "Single Chain Magnet". Inorg. Chem. 2004, 43, 8200-8202. [CrossRef]

31. Sun, Y.-Q.; Zhang, J.; Chen, Y.-M.; Yang, G.-Y. Porous Lanthanide-Organic Open Frameworks with Helical Tubes Constructed from Interweaving Triple-Helical and Double-Helical Chains. Angew. Chem. 2005, 117, 5964-5967. [CrossRef]

32. Ishikawa, N.; Sugita, M.; Ishikawa, T.; Koshihara, S.-y.; Kaizu, Y. Lanthanide Double-Decker Complexes Functioning as Magnets at the Single-Molecular Level. J. Am. Chem. Soc. 2003, 125, 8694-8695. [CrossRef] [PubMed]

33. Sessoli, R.; Powell, A.K. Strategies towards single molecule magnets based on lanthanide ions. Coord. Chem. Rev. 2009, 253, 2328-2341. [CrossRef]

34. Robaschik, P.; Fronk, M.; Toader, M.; Klyatskaya, S.; Ganss, F.; Siles, P.F.; Schmidt, O.G.; Albrecht, M.; Hietschold, M.; Ruben, M.; et al. Tuning the magneto-optical response of $\mathrm{TbPc}_{2}$ single molecule magnets by the choice of the substrate. J. Mater. Chem. C 2015, 3, 8039-8049. [CrossRef]

35. Urdampilleta, M.; Klayatskaya, S.; Ruben, M.; Wernsdorfer, W. Magnetic Interaction Between a Radical Spin and a Single-Molecule Magnet in a Molecular Spin-Valve. ACS Nano 2015, 9, 4458-4464. [CrossRef] [PubMed]

36. Wang, X.; Zhu, M.; Wang, J.; Li, L. Unusual Gd-nitronyl nitroxide antiferromagnetic coupling and slow magnetic relaxation in the corresponding Tb analogue. Dalton Trans. 2015, 44, 13890-13896. [CrossRef] [PubMed]

37. Aguilà, D.; Barrios, L.A.; Luis, F.; Repollés, A.; Roubeau, O.; Teat, S.J.; Aromí, G. Synthesis and Properties of a Family of Unsymmetric Dinuclear Complexes of LnIII ( $\mathrm{Ln}=\mathrm{Eu}, \mathrm{Gd}, \mathrm{Tb})$. Inorg. Chem. 2010, 49, 6784-6786. [CrossRef]

38. Ganivet, C.R.; Ballesteros, B.; de la Torre, G.; Clemente-Juan, J.M.; Coronado, E.; Torres, T. Influence of Peripheral Substitution on the Magnetic Behavior of Single-Ion Magnets Based on Homo- and Heteroleptic TbIII Bis(phthalocyaninate). Chem. Eur. J. 2013, 19, 1457-1465. [CrossRef]

39. Osa, S.; Kido, T.; Matsumoto, N.; Re, N.; Pochaba, A.; Mrozinski, J. A Tetranuclear 3d-4f Single Molecule Magnet: [CuIILTbIII(hfac) $\left.{ }_{2}\right]_{2}$. J. Am. Chem. Soc. 2004, 126, 420-421. [CrossRef]

40. Rinehart, J.D.; Fang, M.; Evans, W.J.; Long, J.R. A $\mathrm{N}_{2}{ }^{3-}$ Radical-Bridged Terbium Complex Exhibiting Magnetic Hysteresis at 14 K. J. Am. Chem. Soc. 2011, 133, 14236-14239. [CrossRef]

41. Bartolomé, E.; Bartolomé, J.; Arauzo, A.; Luzón, J.; Badía, L.; Cases, R.; Luis, F.; Melnic, S.; Prodius, D.; Shova, S.; Turta, C. Antiferromagnetic single-chain magnet slow relaxation in the $\left\{\mathrm{Tb}(\alpha \text {-fur })_{3}\right\} \mathrm{n}$ polymer with non-Kramers ions. J. Mater. Chem. C. 2016, 4, 5038-5050. [CrossRef]

42. Pasca, E.; Roscilde, T.; Evangelisti, M.; Burzurí, E.; Luis, F.; de Jongh, L.J.; Tanase, S. Realization of the one-dimensional anisotropic XY model in a $\mathrm{Tb}(\mathrm{III})-\mathrm{W}(\mathrm{V})$ chain compound. Phys. Rev. B: Condens. Matter Mater. Phys. B 2012, 85, 184434. [CrossRef]

43. Liu, R.; Zhang, C.; Mei, X.; Hu, P.; Tian, H.; Li, L.; Liao, D.; Sutter, J.-P. Slow magnetic relaxation and antiferromagnetic ordering in a one-dimensional nitronyl nitroxide-Tb(iii) chain. New J. Chem. 2012, 36, 2088-2093. [CrossRef]

44. Hu, P.; Wang, X.; Ma, Y.; Wang, Q.; Li, L.; Liao, D. A new family of Ln-radical chains ( $\mathrm{Ln}=\mathrm{Nd}, \mathrm{Sm}, \mathrm{Gd}$, $\mathrm{Tb}$ and Dy): Synthesis, structure, and magnetic properties. Dalton Trans. 2014, 43, 2234-2243. [CrossRef] [PubMed]

45. Bartolomé, E.; Bartolomé, J.; Arauzo, A.; Luzón, J.; Cases, R.; Fuertes, S.; Sicilia, V.; Sánchez-Cano, A.I.; Aporta, J.; Melnic, S.; et al. Heteronuclear $\{$ TbxEu1-x\} furoate 1D polymers presenting luminescent properties and SMM behavior. J. Mater. Chem. 2018, 6, 5286-5299. [CrossRef]

46. Wang, Y.-W.; Liu, S.-B.; Yang, Y.-L.; Wang, P.-Z.; Zhang, A.-J.; Peng, Y. A Terbium(III)-Complex-Based On-Off Fluorescent Chemosensor for Phosphate Anions in Aqueous Solution and Its Application in Molecular Logic Gates. ACS Appl. Mater. Interfaces. 2015, 7, 4415-4422. [CrossRef]

47. Liu, Z.; He, W.; Guo, Z. Metal coordination in photoluminescent sensing. Chem. Soc. Rev. 2013, 42, 1568-1600. [CrossRef] [PubMed]

48. Muller, G. Luminescent chiral lanthanide(iii) complexes as potential molecular probes. Dalton Trans. 2009, 44, 9692-9707. [CrossRef]

49. Accorsi, G.; Listorti, A.; Yoosaf, K.; Armaroli, N. 1,10-Phenanthrolines: Versatile building blocks for luminescent molecules, materials and metal complexes. Chem. Soc. Rev. 2009, 38, 1690-1700. [CrossRef] 
50. Zhang, X.; Liu, S.; Vieru, V.; Xu, N.; Gao, C.; Wang, B.-W.; Shi, W.; Chibotaru, L.F.; Gao, S.; Cheng, P.; et al. Coupling Influences SMM Properties for Pure 4 f Systems. Chem. Eur. J. 2018, 24, 6079-6086. [CrossRef]

51. Alvarez, S.; Alemany, P.; Casanova, D.; Cirera, J.; Llunell, M.; Avnir, D. Shape maps and polyhedral interconversion paths in transition metal chemistry. Coord. Chem. Rev. 2005, 249, 1693-1708. [CrossRef]

52. Li, Y.; Zhao, P.; Zhang, S.; Li, R.; Zhang, Y.-Q.; Yang, E.-C.; Zhao, X.-J. A Rare Water and Hydroxyl-Extended One-Dimensional Dysprosium(III) Chain and Its Magnetic Dilution Effect. Inorg. Chem. 2017, 56, 9594-9601. [CrossRef] [PubMed]

53. Roy, S.; Bauza, A.; Frontera, A.; Schaper, F.; Banik, R.; Purkayastha, A.; Reddy, B.M.; Sridhar, B.; Drew, M.G.B.; Das, S.K.; et al. Structural diversity and non-covalent interactions in Cd(II) and Zn(II) complexes derived from 3,5-dinitrobenzoic acid and pyridine: Experimental and theoretical aspects. Inorg. Chim. Acta 2016, 440, 38-47. [CrossRef]

54. Roy, S.; Oyarzabal, I.; Vallejo, J.; Cano, J.; Colacio, E.; Bauza, A.; Frontera, A.; Kirillov, A.M.; Drew, M.G.B.; Das, S. Two Polymorphic Forms of a Six-Coordinate Mononuclear Cobalt(II) Complex with Easy-Plane Anisotropy: Structural Features, Theoretical Calculations, and Field-Induced Slow Relaxation of the Magnetization. Inorg. Chem. 2016, 55, 8502-8513. [CrossRef] [PubMed]

55. Kahn, O. Molecular Magnetism; Wiley-VCH: Weinheim, Germany, 1993.

56. Bera, S.P.; Mondal, A.; Roy, S.; Dey, B.; Santra, A.; Konar, S. 3D isomorphous lanthanide coordination polymers displaying magnetic refrigeration, slow magnetic relaxation and tunable proton-conduction. Dalton Trans. 2018. [CrossRef] [PubMed]

57. Sheikh, J.A.; Goswami, S.; Konar, S. Modulating the magnetic properties by structural modification in a family of Co-Ln (Ln = Gd, Dy) molecular aggregates. Dalton Trans. 2014, 43, 14577-14585. [CrossRef] [PubMed]

58. Chilton, N.F.; Anderson, R.P.; Turner, L.D.; Soncini, A.; Murray, K.S. PHI: A powerful new program for the analysis of anisotropic monomeric and exchange-coupled polynuclear $\mathrm{d}$ - and f-block complexes. J. Comput. Chem. 2013, 34, 1164-1175. [CrossRef] [PubMed]

59. Goswami, S.; Adhikary, A.; Jena, H.S.; Konar, S. Lanthanide based coordination polymers chill, relax under magnetic field and also fluoresce. Dalton Trans. 2013, 42, 9813-9817. [CrossRef]

60. Biswas, S.; Chakraborty, J.; Singh Parmar, V.; Bera, S.P.; Ganguli, N.; Konar, S. Channel-Assisted Proton Conduction Behavior in Hydroxyl-Rich Lanthanide-Based Magnetic Metal-Organic Frameworks. Inorg. Chem. 2017, 56, 4956-4965. [CrossRef]

61. Dey, A.; Das, S.; Palacios, M.A.; Colacio, E.; Chandrasekhar, V. Single-Molecule Magnet and Magnetothermal Properties of Two-Dimensional Polymers Containing Heterometallic [Cu5Ln2] (Ln = GdIII and DyIII) Motifs. Eur. J. Inorg. Chem. 2018, 1645-1654. [CrossRef]

62. She, S.; Gong, L.; Wang, B.; Yang, Y.; Lei, Q.; Liu, B.; Su, G. Slow magnetic relaxation in a two-dimensional dysprosium(III) coordination polymer. Inorg. Chem. Commun. 2016, 70, 18-21. [CrossRef]

63. Zhu, L.-L.; Hu, P.; Cao, J.-F.; Zhao, Y.-H.; Wu, Y.-N.; Zhu, Y.-X.; Su, Y.; Wang, C. Magnetic relaxation in mononuclear $\mathrm{Tb}$ and Dy complexes involving chelate nitronyl nitroxide ligand. Polyhedron 2018, 155, 375-381. [CrossRef]

64. Mondal, P.; Dey, B.; Roy, S.; Bera, S.P.; Nasani, R.; Santra, A.; Konar, S. Field-Induced Slow Magnetic Relaxation and Anion/Solvent Dependent Proton Conduction in Cobalt(II) Coordination Polymers. Cryst. Growth Des. 2018, 18, 6211-6220. [CrossRef]

65. Gupta, S.K.; Rajeshkumar, T.; Rajaraman, G.; Murugavel, R. Is a strong axial crystal-field the only essential condition for a large magnetic anisotropy barrier? The case of non-Kramers Ho(iii) versus $\mathrm{Tb}(\mathrm{iii})$. Dalton Trans. 2018, 47, 357-366. [CrossRef] [PubMed]

66. Vieru, V.; Ungur, L.; Cemortan, V.; Sukhanov, A.; Baniodeh, A.; Anson, C.E.; Powell, A.K.; Voronkova, V.; Chibotaru, L. Magnetization Blocking in $\mathrm{Fe}_{2} \mathrm{IIIDy} 2 \mathrm{III}$ Molecular Magnets: Ab initio Calculations and EPR. Chem. Eur. J. 2018, 0. [CrossRef] [PubMed]

67. Langley, S.K.; Wielechowski, D.P.; Vieru, V.; Chilton, N.F.; Moubaraki, B.; Abrahams, B.F.; Chibotaru, L.F.; Murray, K.S. A $\left\{\mathrm{Cr}_{2}{ }_{2}{ }_{2 y}{ }^{\mathrm{III}}{ }_{2}\right\}$ Single-Molecule Magnet: Enhancing the Blocking Temperature through $3 \mathrm{~d}$ Magnetic Exchange. Angew. Chem. Int. Ed. 2013, 52, 12014-12019. [CrossRef]

68. Vieru, V.; Ungur, L.; Chibotaru, L.F. Key Role of Frustration in Suppression of Magnetization Blocking in Single-Molecule Magnets. J. Phys. Chem. Lett. 2013, 4, 3565-3569. [CrossRef] 
69. Bünzli, J.-C.G.; Piguet, C. Lanthanide-Containing Molecular and Supramolecular Polymetallic Functional Assemblies. Chem. Rev. 2002, 102, 1897-1928. [CrossRef]

70. Moore, E.G.; Samuel, A.P.S.; Raymond, K.N. From Antenna to Assay: Lessons Learned in Lanthanide Luminescence. Acc. Chem. Res. 2009, 42, 542-552. [CrossRef]

71. Hovinen, J.; Guy, P.M. Bioconjugation with Stable Luminescent Lanthanide(III) Chelates Comprising Pyridine Subunits. Bioconjugate Chem. 2009, 20, 404-421. [CrossRef]

72. Bünzli, J.-C.G.; Piguet, C. Taking advantage of luminescent lanthanide ions. Chem. Soc. Rev. 2005, 34, 1048-1077. [CrossRef] [PubMed]

73. Eliseeva, S.V.; Bünzli, J.-C.G. Lanthanide luminescence for functional materials and bio-sciences. Chem. Soc. Rev. 2010, 39, 189-227. [CrossRef] [PubMed]

74. Mondal, A.K.; Goswami, S.; Konar, S. Influence of the coordination environment on slow magnetic relaxation and photoluminescence behavior in two mononuclear dysprosium(iii) based single molecule magnets. Dalton Trans. 2015, 44, 5086-5094. [CrossRef] [PubMed]

75. Biju, S.; Gopakumar, N.; Bünzli, J.C.G.; Scopelliti, R.; Kim, H.K.; Reddy, M.L.P. Brilliant Photoluminescence and Triboluminescence from Ternary Complexes of DyIII and TbIII with 3-Phenyl-4-propanoyl-5isoxazolonate and a Bidentate Phosphine Oxide Coligand. Inorg. Chem. 2013, 52, 8750-8758. [CrossRef] [PubMed]

76. Gu, J.-Z.; Wu, J.; Lv, D.-Y.; Tang, Y.; Zhu, K.; Wu, J. Lanthanide coordination polymers based on 5-(2'-carboxylphenyl) nicotinate: Syntheses, structure diversity, dehydration/hydration, luminescence and magnetic properties. Dalton Trans. 2013, 42, 4822-4830. [CrossRef] [PubMed]

77. Goswami, S.; Biswas, S.; Tomar, K.; Konar, S. Tuning the Magnetoluminescence Behavior of Lanthanide Complexes Having Sphenocorona and Cubic Coordination Geometries. Eur. J. Inorg. Chem. 2016, 2016, 2774-2782. [CrossRef]

78. Dolomanov, O.V.; Bourhis, L.J.; Gildea, R.J.J.; Howard, A.K.; Puschmann, H. A complete structure solution, refinement and analysis program. J. Appl. Cryst. 2009, 42, 339-341. [CrossRef]

79. Sheldrick, G.M. Crystal structure refinement with ShelXL. Acta Cryst. C 2015, 27, 30-38.

(C) 2018 by the authors. Licensee MDPI, Basel, Switzerland. This article is an open access article distributed under the terms and conditions of the Creative Commons Attribution (CC BY) license (http:/ / creativecommons.org/licenses/by/4.0/). 